\title{
Theoretical Model for the EM Effects Induced By High-Energy Photons (Gamma, X-ray) in Dielectric Materials and Electronic Systems
}

J. H. Yee, D. J. Mayhall, M. F. Bland

\section{August 3, 2001}

U.S. Department of Energy

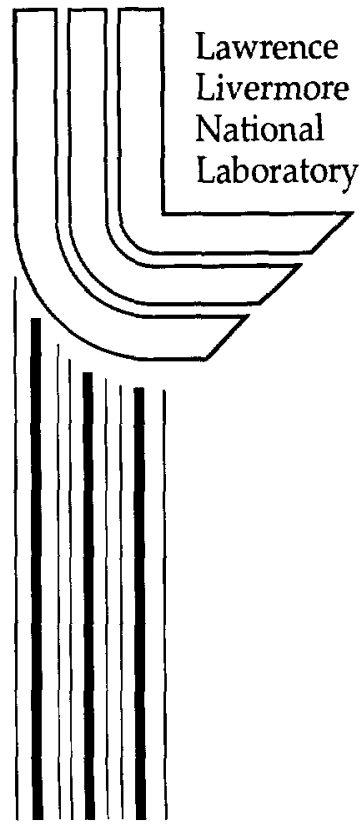




\section{DISCLAIMER}

This document was prepared as an account of work sponsored by an agency of the United States Government. Neither the United States Government nor the University of California nor any of their employees, makes any warranty, express or implied, or assumes any legal liability or responsibility for the accuracy, completeness, or usefulness of any information, apparatus, product, or process disclosed, or represents that its use would not infringe privately owned rights. Reference herein to any specific commercial product, process, or service by trade name, trademark, manufacturer, or otherwise, does not necessarily constitute or imply its endorsement, recommendation, or favoring by the United States Government or the University of California. The views and opinions of authors expressed herein do not necessarily state or reflect those of the United States Government or the University of California, and shall not be used for advertising or product endorsement purposes.

This work was performed under the auspices of the U.S. Department of Energy by the University of California, Lawrence Livermore National Laboratory under Contract No. W-7405-Eng-48.

This report has been reproduced directly from the best available copy.

Available electronically dttp://www.doc.gov/bridge

Available for a processing fee to U.S. Department of Energy

And its contractors in paper from

U.S. Department of Energy

Office of Scientific and Technical Information

P.O. Box 62

Oak Ridge, TN 37831-0062

Telephone: (865) 576-8401

Facsimile: (865) 576-5728

E-mail:reports@adonis.osti.gov

Available for the sale to the public from

U.S. Department of Commerce

National Technical Information Service

5285 Port Royal Road

Springfield, VA 22161

Telephone: (800) 553-6847

Facsimile: (703) 605-6900

E-mail:orders@ntis.fedworld.gov

Online ordering: http://www.ntis.gov/ordering.htm

\section{OR}

Lawrence Livermore National Laboratory

Technical Information Department's Digital Library

http://www.llnl.gov/tid/Library.html 
Theoretical Model for the EM Effects Induced By HighEnergy Photons (Gamma, X-ray) in Dielectric Materials and Electronic Systems

\author{
By: \\ Jick H. Yee, David J. Mayhall, and Mike F. Bland \\ Lawrence Livermore National Laboratory \\ (LLNL)
}

August 3, 2001 


\section{Theoretical Model for the EM Effects Induced By High-Energy Photons in Dielectric Materials and Electronic Systems Jick H. Yee, David J. Mayhall, and Mike F. Bland Lawrence Livermore National Laboratory}

\section{Introduction}

During last twenty years, a number of models have been used to calculate the change of conductivity and dielectric strength in materials caused by the passage of high-energy photons, such as Gamma-rays and X-rays. In these models, the electromagnetic fields generated in the electronic system created by the high-energy photons have not been investigated. That is, the solution of Maxwell's equations has not been obtained for these kinds of problems. We constructed a theoretical model, described by a set of equations to solve such a problem. The model includes the equations that describe the physics of the recombination and generation of electron-hole pairs by the high-energy photons in the dielectric materials, the Compton electron generation rates, and Maxwell's equations.

When a beam of gamma photons penetrates into a transmission line or cables, energetic electrons and holes (carriers) are created in the metals and dielectrics of the system by the Compton and photoelectric effects. These energetic electrons and holes in turn create many low-energy holes and electrons through the interaction of the high-energy electrons with the atoms in the solids. Since the density of the solids is very high, the mean free path of the high-energy electrons is very short. In other words, they lose their energy in a very short-time, on the order of picoseconds or less. Since electronic systems typically do not respond in such a short time, we can make the approximation that the number of lowenergy carriers can be determined by energy deposition by the gamma photons with the use of a Monte Carlo code and then divide the deposited energy by the average amount of energy necessary to create an electron-hole pair. Then in order to investigate how the electromagnetic wave is created by the gamma photons and its behavior as it propagates through the electronic system, we have considered the various recombination and trapping processes of the electrons and holes in the dielectric material.

We modified an implicit, two-dimensional, finite difference, time domain, electromagnetic, electron fluid computer code for the propagation of transverse electromagnetic (TEM) and transverse magnetic (TM) modes in a parallel plate transmission line in a rectangular geometry with pressure-variable air as the dielectric material. In the modified code, the single dielectric medium between the perfectly conducting metal plates is a solid dielectric with electron trapping and de-trapping, recombination, and radiation induced conductivity. Primary, high-energy electron and secondary, low-energy, conduction electron current densities are included in the modified equations. We obtained axial propagation of a primarily TEM wave when the entrance of the transmission line is obliquely illuminated with a step gamma pulse in time.

In order to model to first order in two dimensions a coaxial cable, we have also developed a radial geometry code with two different solid dielectrics between a cylindrical center conductor and an annular outer shield conductor. Both conductors are 
presently considered to be perfectly electrically conducting. The first problem that we considered for the gamma radiation effects is for a coaxial cable. We obtained electromagnetic wave propagation for gamma ray illumination about the axial mid-point of a two-dielectric coaxial cable model with a step pulse in time with a strong Gaussian distribution in the axial direction and gamma attenuation in the negative radial direction. Electromagnetic waves propagate out in the positive and negative axial directions. Figure 1 is a surface plot of the $E_{\mathrm{r}}$ field generated by the gamma near the axial midpoint of the two-dielectric coaxial cable at $1 \times 10^{-16} \mathrm{sec}$. The cable is $0.531 \mathrm{~m}$ long and 0.0568 $\mathrm{cm}$ at the outer dielectric radius. The discontinuity in the peak $\mathrm{E}_{\mathrm{r}}$ indicates the radial discontinuity in the dielectric constant. Figure 2 is a surface plot of $E_{r}$ at $1.5 \times 10^{-9} \mathrm{sec}$. Two wave peaks at $r=0.0346 \mathrm{~cm}$ are seen moving toward the ends of the coaxial cable at $z=0$ and $z=0.531 \mathrm{~m}$. The peak $\mathrm{E}_{\mathrm{r}}$ occurs near dielectric interface at the axial midpoint. 
time $=\emptyset .10000 \mathrm{E}-15 \mathrm{sec}$

Calculated Ermax $=-\varnothing .10143 \mathrm{E}-18 \mathrm{~V} / \mathrm{m}$

Calculated Ermin $=\varnothing .31790 \mathrm{E}-24 \mathrm{~V} / \mathrm{m}$

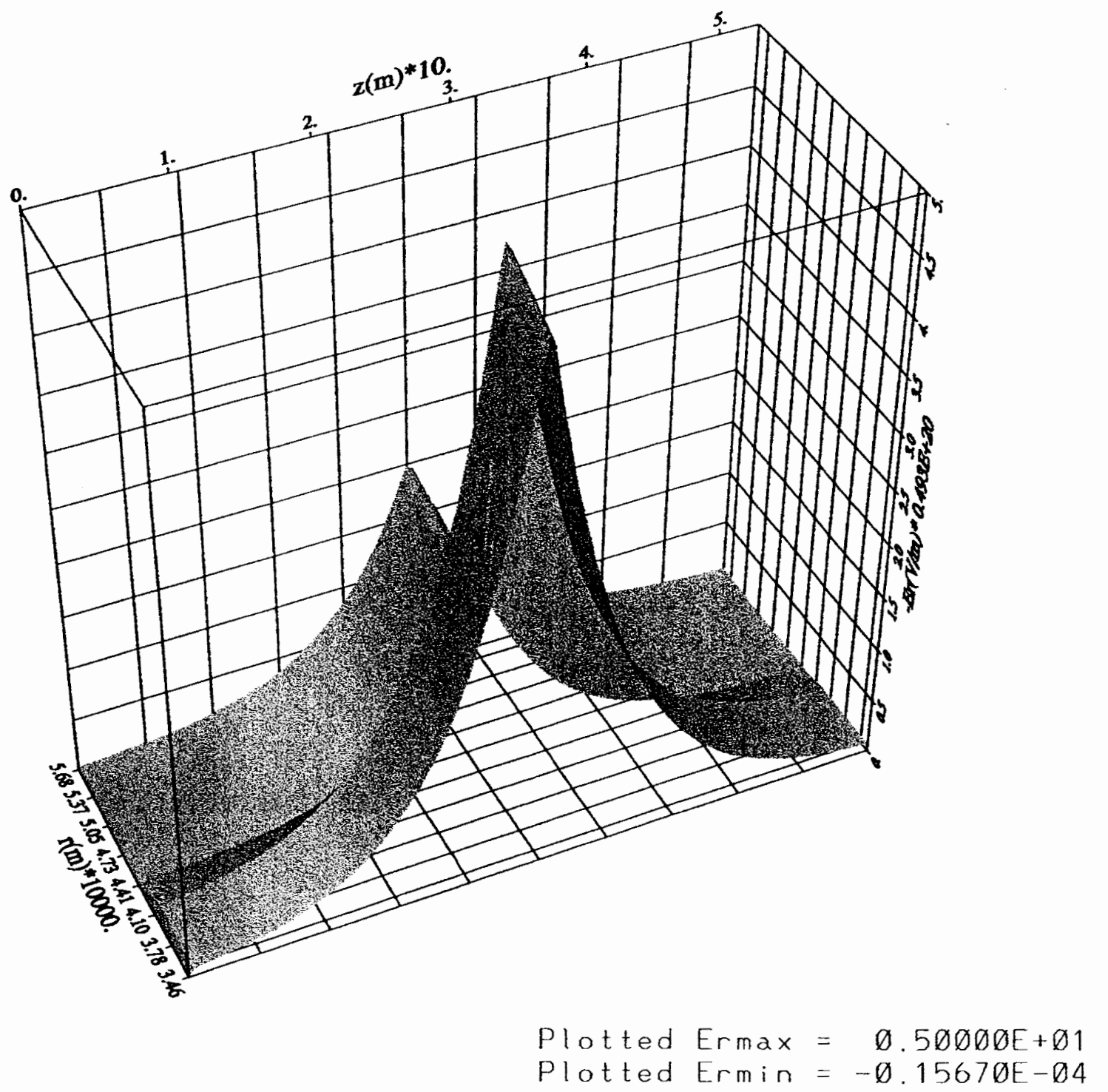

Figure 1 . Surface plot of the $\mathrm{E}_{\mathrm{r}}$ field generated by the gamma near the axial midpoint of the two-dielectric coaxial cable at $1 \times 10^{-16} \mathrm{sec}$. 
time $=\emptyset .15000 \mathrm{E}-08 \mathrm{sec}$

Calculated Ermax $=-\emptyset .62901 E-12 \mathrm{~V} / \mathrm{m}$

Calculated Ermin $=0.21551 \mathrm{E}-12 \mathrm{~V} / \mathrm{m}$

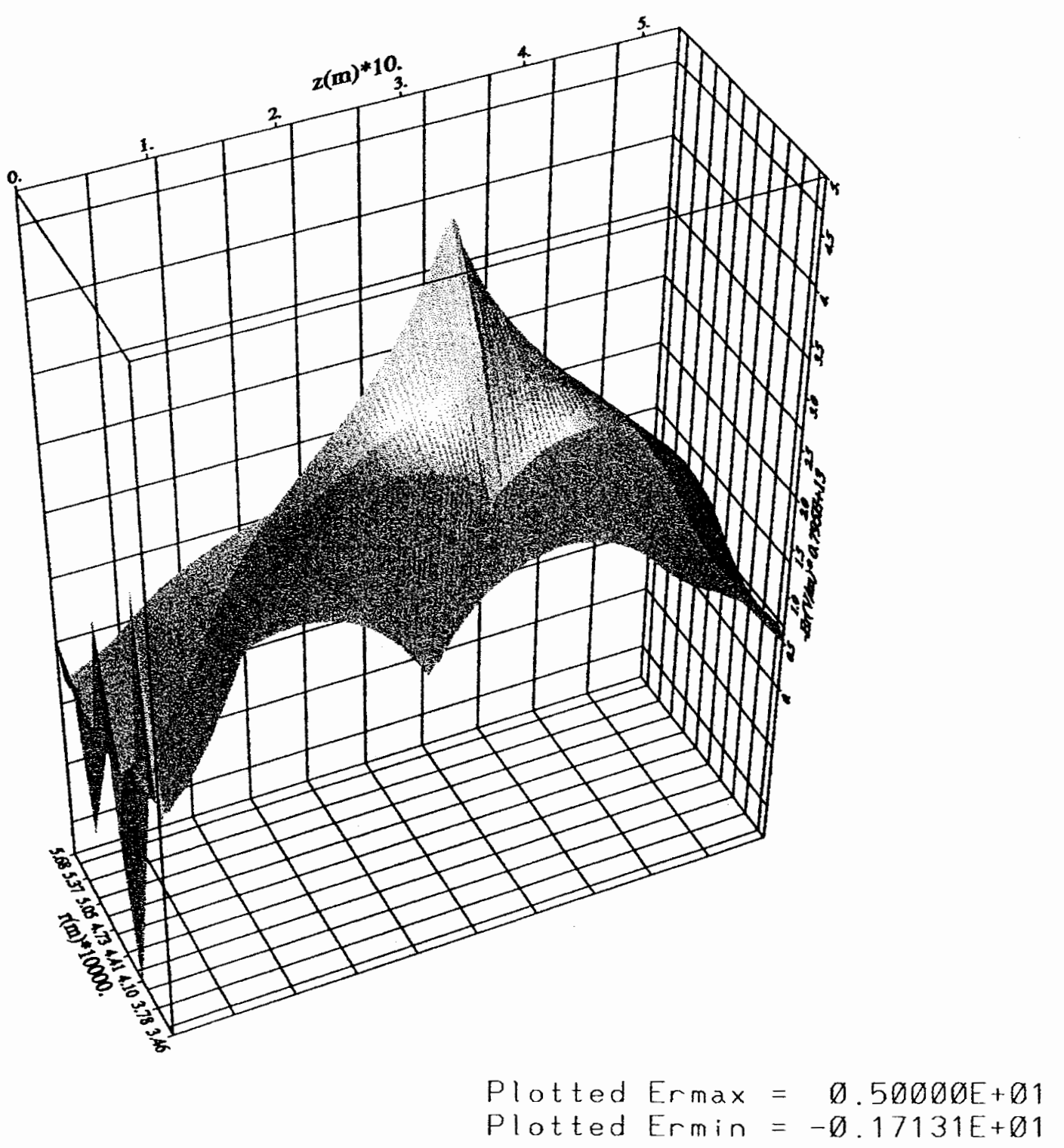

Figure 2 Surface plot of $E_{r}$ of the two-dielectric coaxial cable at $1.5 \times 10^{-9} \mathrm{sec}$. 